\title{
Long-Term Effects of Vitamin D Supplementation in Obese Children During Integrated Weight-Loss Programme-A Double Blind Randomized Placebo-Controlled Trial
}

\author{
Michał Brzeziński ${ }^{1,2, *}$,, Agnieszka Jankowska ${ }^{1}$, Magdalena Słomińska-Frączek ${ }^{3}$, \\ Paulina Metelska ${ }^{2,4}$, Piotr Wiśniewski ${ }^{5}$, Piotr Socha ${ }^{6}$ and Agnieszka Szlagatys-Sidorkiewicz ${ }^{1}$ (I) \\ 1 Department of Paediatrics, Gastroenterology, Allergology and Paediatric Nutrition, Medical University of \\ Gdańsk, 80-803 Gdańsk, Poland; ajankowska@gumed.edu.pl (A.J.); \\ agnieszka.szlagatys-sidorkiewicz@gumed.edu.pl (A.S.-S.) \\ 2 Department of Public Health and Social Medicine, Medical University of Gdansk, 80-210 Gdańsk, Poland; \\ metelska.paulina@gumed.edu.pl \\ 3 Department of Paediatrics, Copernicus Medical Center, 80-462 Gdańsk, Poland; madds@wp.pl \\ 4 "6-10-14 for Health"-University Clinical Center, 80-952 Gdańsk, Poland \\ 5 Department of Endocrinology and Internal Medicine, Medical University of Gdansk, 80-952 Gdańsk, Poland; \\ piotr.wisniewski@gumed.edu.pl \\ 6 Department of Gastroenterology, Hepatology and Feeding Disorders, The Children's Memorial Health \\ Institute, 04-730 Warszawa, Poland; p.socha@ipczd.pl \\ * Correspondence: brzezinski@gumed.edu.pl; Tel.: +48-501-762-172
}

Received: 24 March 2020; Accepted: 13 April 2020; Published: 15 April 2020

check for updates

\begin{abstract}
Background: Vitamin D was studied in regards to its possible impact on body mass reduction and metabolic changes in adults and children with obesity yet there were no studies assessing the impact of vitamin D supplementation during a weight management program in children and adolescence. The aim of our study was to assess the influence of 26 weeks of vitamin D supplementation in overweight and obese children undergoing an integrated 12-months' long weight loss program on body mass reduction, body composition and bone mineral density. Methods: A double-blind randomized placebo-controlled trial. Vitamin D deficient patients ( $<30 \mathrm{ng} / \mathrm{ml}$ level of vitamin D) aged 6-14, participating in multidisciplinary weight management program were randomly allocated to receiving vitamin D (1200 IU) or placebo for the first 26 weeks of the intervention. Results: Out of the 152 qualified patients, 109 (72\%) completed a full cycle of four visits scheduled in the program. There were no difference in the level of BMI (body mass index) change - both raw BMI and BMI centiles. Although the reduction of BMI centiles was greater in the vitamin D vs. placebo group $(-4.28 \pm 8.43$ vs. $-2.53 \pm 6.10)$ the difference was not statistically significant $(p=0.319)$. Similarly the reduction in fat mass-assessed both using bioimpedance and DEXa was achieved, yet the differences between the groups were not statistically significant. Conclusions: Our study ads substantial results to support the thesis on no effect of vitamin D supplementation on body weight reduction in children and adolescents with vitamin D insufficiency undergoing a weight management program.
\end{abstract}

Keywords: vitamin D; obesity; weight-loss; body composition

\section{Introduction}

Worldwide prevalence of overweight and obesity is increasing both in adults and children [1,2]. It is observed on all continents, with the highest burden in those from lower socioeconomic and educational groups [1,3]. Obesity among others is associated with a wide range of metabolic disorders, such as 
insulin resistance, hyperinsulinemia, and impaired tolerance of glucose, abnormal fasting plasma glucose, symptomatic diabetes mellitus, lipid disorders and cardiovascular disorders, namely arterial hypertension [4-6]. Obesity alone is responsible for a significant increase in the risk of mortality in general population with [7]. In view of high risk of complications resulting from childhood obesity, early implementation of intervention programs seems to be vitally important, as in children and adolescents it is the first-choice intervention, although with limited effectiveness [8]. Several previous studies showed that integrated multidisciplinary weight-loss programs, which include the child's family as well, are the most effective [9-11]. Reduction of fat mass is associated with normalization of metabolic parameters, such as inflammatory markers, lipid profile, insulin resistance and arterial blood pressure [12-14]. Therefore, early and efficient intervention increases likelihood of staying healthy in the future. As pharmacological and surgical interventions in children are limited [15-17], trials looking for substances supporting lifestyle interventions were run, looking at several different dietary supplements, hers (green tea, yerba mate), DHA (docosahexaenoic acid) among others [18-22]. Vitamin D was also studied in regards to its possible impact on body mass reduction and metabolic changes in adults and children with obesity $[23,24]$.

The role of vitamin $\mathrm{D}$ in energetic metabolism has been emphasized recently. Obese children frequently present with low blood concentrations of vitamin D [25-27]. This probably results from lower dietary intake of this vitamin by obese individuals on the one hand, and less outdoor physical activity on the other [28-30]. Moreover, a higher percentage of fat mass is associated with a lower blood concentration of vitamin D, which may, at least partially, result from its sequestration in adipose tissue [31]. Animal experiments with labelled vitamin D showed that this vitamin is accumulated in adipose tissue and slowly released to blood [32].

Consequently, a vitamin $\mathrm{D}$ deficiency in obese children seems to be associated with a significant increase of risk of many metabolic disorders associated with obesity, such as insulin resistance, hyperinsulinemia, impaired tolerance of glucose, abnormal fasting plasma glucose, symptomatic diabetes mellitus, lipid disorders and cardiovascular morbidity, namely arterial hypertension $[5,6]$. There is a number of observational studies which demonstrate the substantial role of vitamin $D$ deficiency in developing metabolic syndrome and other complications of obesity [33-35]. However, we lack interventional studies to link these observations to demonstrate a causal relationship.

In this study we wanted to assess the influence of 26 weeks of vitamin D supplementation in overweight and obese children undergoing an integrated 12-months' long weight loss program on body mass reduction, body composition and bone mineral density [36].

\section{Materials and Methods}

Detailed information about the study protocol, participants and design of the interventional program has been previously published [36]. All study participants were recruited from "6-10-14 for Health" program run by University Clinical Center in Gdansk, Poland. The program is a multidisciplinary, interventional program dedicated to children aged 6-15 and their parents. All school children in Gdansk aged 6-15 are screened in a 3-4-year-interval by dedicated teams (pediatrician and or nurses). All children with BMI centile above $85^{\text {th }}$ centile are invited to the "6-10-14 for Health" program. All participants of the "6-10-14 for Health" program and their family members (parents/caregivers) were offered 12-month integrated intervention, including individual medical (pediatric), dietetic, physical activity and psychological counselling, during one meeting (4 x 20-25min). This intervention was offered to all the participants in a 0-3-6-12 month scheme.

\subsection{Trial Design}

A double-blind placebo-controlled trial. Vitamin D deficient patients ( $<30 \mathrm{ng} / \mathrm{ml}$ level of vitamin D) participating in multidisciplinary weight program were randomized to two arms (1:1 ratio): receiving vitamin $\mathrm{D}(1200 \mathrm{IU})$ or placebo for the first 26 weeks of the intervention. 
We hypothesized that the supplementation with vitamin $\mathrm{D}$ in obese children showing low serum 25(OH)D3 during weight-loss program could positively influence body mass index (BMI), muscle mass, bone mass and mineral density and biochemical markers of metabolic complications related to obesity compared to placebo.

The study was conducted at the Department of Paediatrics, Paediatric Gastroenterology, Allergology and Children Nutrition, the Medical University of Gdansk and within the framework of "6-10-14 for Health" Interventional Programme, University Clinical Centre in Gdansk.

\subsection{Participants}

Eligible participants were children aged 6, 9-11 and 14, according to the "6-10-14 for Health" program protocol:

Inclusion criteria: overweight (BMI $\geq 85$ th $<95$ th percentile) or obesity (BMI $\geq 95$ th percentile), identified on the basis of anthropometric parameters using Polish reference centile charts-OLAF project [37]; blood concentration of $25(\mathrm{OH}) \mathrm{D} 3<30 \mathrm{ng} / \mathrm{ml}$; written informed consent of legal caregivers.

Exclusion criteria: Chronic conditions (asthma or allergies, inflammatory diseases of connective tissue, gastrointestinal disorders, diseases of kidneys and liver, disorders of bone metabolism); contraindications to administration of vitamin $\mathrm{D}$; administration of any preparation containing vitamin $\mathrm{D}$, calcium, or steroid hormones during three months preceding the study.

\subsection{Ethics Approval and Consent to Participate}

The study is approved by Independent Bioethics Committee for Scientific Research at Medical University of Gdansk, Poland, [NKBBN/130-206/2015] dated 25.05.2015. The parents/caregivers gave their written consent before the start of any study procedure. The study protocol was peer reviewed by financial supporter (Fundacja Nutricia) independent commission, during the grant application process. Trial registration no: NCT 02828228; trial registration date: 8 June 2016 registered in: ClinicalTrials.gov.

\subsection{Study Procedure}

The study period covered four appointments within the "6-10-14 for Health" obesity management program at the 0,3,6 and 12 month mark. All visits included individual meetings with a pediatrician, dietician, physical activity specialist and psychologist. All child/parent dyads had individual meetings with all 4 specialists - one directly after other. Detailed information about the program can be found in previous publications [36]. During the first appointment, the caregivers of all children were asked to provide written consent to the child taking part in the trial. Refusal to participate in the trial did not influence participation in the interventional obesity management program. Children with low blood concentration of 25(OH)D3 $(<30 \mathrm{ng} / \mathrm{ml}$ ) were referred for DXA (dual-energy x-ray absorptiometry) within two weeks from the starting visit.

The enrolled subjects were randomly assigned to one of the two groups using computer generated randomization tables. Then participants were randomly assigned to one of the two trial groups:

- GROUP I (Vitamin D group): medical intervention, intervention of dietician, psychologist and physical education specialist, parental education + oral administration of vitamin D3 (1200 i.u. daily) for 26 weeks

- GROUP II (Placebo group): medical intervention, intervention of dietician, psychologist and physical education specialist, parental education + daily oral administration of placebo for 26 weeks.

Study time line chart is shown in Figure 1. 


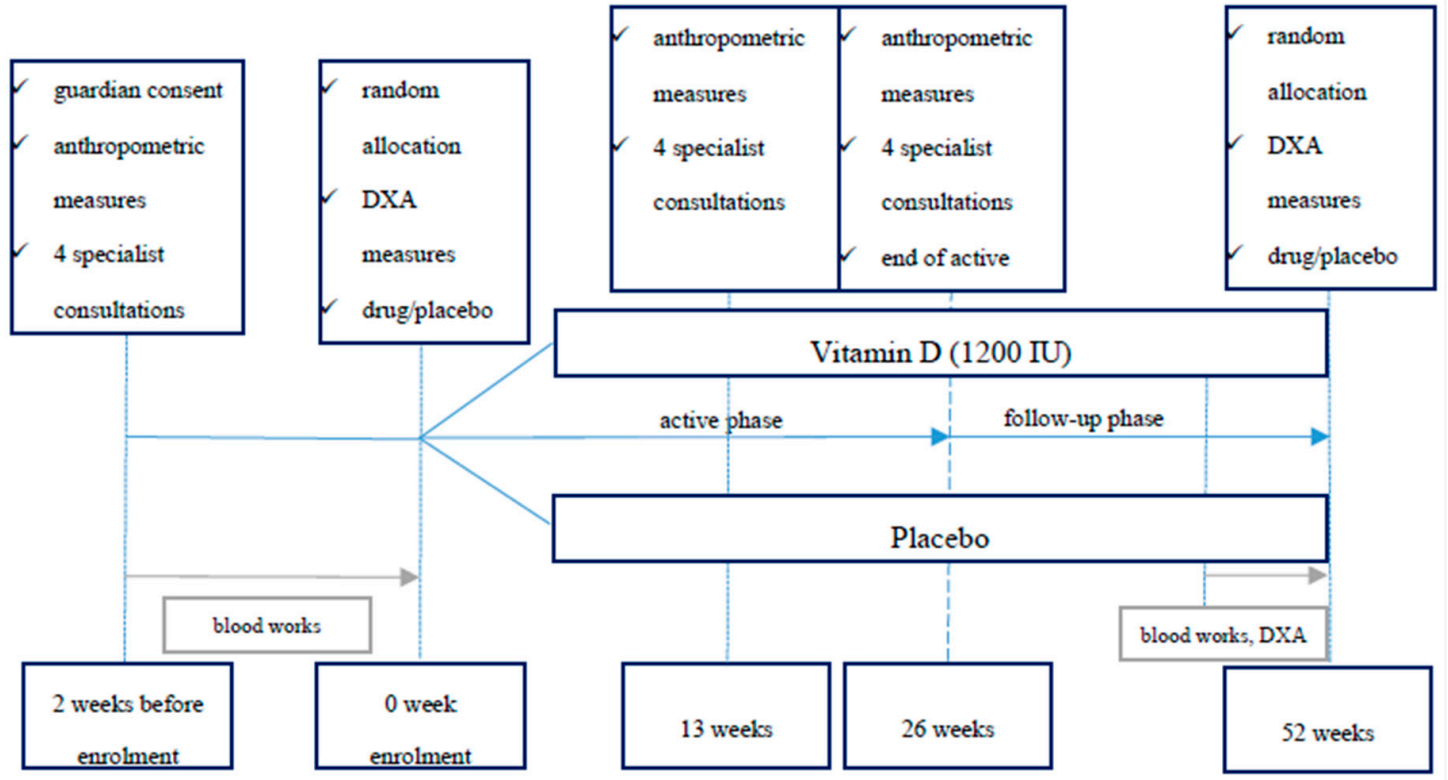

Figure 1. Patients' time line in the study.

\subsection{Randomization and Blinding}

The randomization list was generated by Office of Clinical and Scientific Research, University Clinical Centre (OCSR UCK), with no clinical involvement in the trial, via a computer program (StatsDirect) with an allocation ratio of 1:1 and with a block of 6 . The allocation sequence was concealed from the researchers responsible for enrolling and assessing participants. Throughout the duration of the study, all investigators, participants, outcome assessors, and data analysts were blinded to the assigned treatment. Allocation to groups and drug/placebo distribution was performed by an independent researcher (M.S-F) not directly involved in the interventional program.

\subsection{Treatment Dispensing and Assessment of Compliance}

Both of the study treatments: vitamin D (1200 IU) and placebo were provided by the company (Sequoia) in identical capsules and packages ( 5 capsules in one blister, 6 blisters in a box). The sets of 7 boxes (6 months treatment) were prepared and blinded by Office of Clinical and Scientific Research, University Clinical Centre. Study treatment was dispensed by the investigator at the enrolment visit. At the final visit the sets of blisters and boxes were retrieved from the patient. The number of remaining capsules were documented to assess the compliance.

\subsection{Outcome Measures}

Primary endpoint: Change in BMI, BMI centile after 26 weeks of vitamin D supplementation. Secondary endpoints: change in body composition and bone mineral density and vitamin D level after 26 weeks of vitamin D supplementation. Additionally, we assessed changes in blood level of vitamin D.

\subsection{Sample Size}

Assuming probability of the event (at least 10\% reduction in baseline BMI over the follow-up period) at 0.85 and 0.6 for the experimental and control group, respectively, minimum sample size providing 0.9 statistical power for alpha equal 0.05 or lower and beta equal 0.1 or lower was estimated at 130 (65 per group). 


\subsection{Statistical Analysis}

Normal distribution of continuous variables was verified with the Shapiro-Wilk test. Descriptive statistics are presented as the mean or median and standard deviation from the mean. Between groups comparisons were carried out using the Mann-Whitney $U$ test. Nonparametric tests were chosen because of the large number of significant Shapiro tests, which were used for normality assumption assessment. All statistical tests were two-tailed and performed at the 5\% level of significance. All analyses were performed on the intention-to-treat basis, in which all of the participants in a trial are analyzed according to the intervention to which they were assigned, analyzing only participants who completed the whole weight management intervention program. Statistical analyses were performed with the Statistica 13 (TIBCO Software Inc., Tulsa, USA 2017).

\section{Results}

After obtaining and verifying the correctness of the recorded data (cross-checked with source data of $30 \%$ of patients), the data was decoded according to the protocol received from OCSR UCK in Gdansk.

After decoding, a full analysis of available anthropometric data and the results of densitometric examination was performed for patients divided into groups-receiving placebo and vitamin D.

A total of 170 patients were eligible for enrolment in the study during the enrolment period. A total of 152 patients were eventually included in the study $(n=8-$ no parental consent, $n=10-v i t a m i n ~ D$ intake during three months before the study). Subsequently the patients were randomly assigned to groups: 67 to the placebo group and 85 to the Vitamin D group. Out of the 152 qualified patients, 109 (72\%) completed a full cycle of four visits scheduled in the program. In the placebo group, 64 patients completed the active phase of 26 weeks of supplementation, 53 completed the comprehensive treatment program (52 week duration).

The patient flow is shown in Figure 2.

Basic demographic and clinical data for both groups are presented in Table 1.

Table 1. Basic anthropometric and clinical data of studied groups (vitamin D and placebo) at visit 1.

\begin{tabular}{|c|c|c|c|c|c|}
\hline & \multicolumn{2}{|c|}{ vitamin $\mathrm{D}(n=85)$} & \multicolumn{2}{|c|}{ placebo $(n=67)$} & \multirow[b]{2}{*}{$p$} \\
\hline & Mean \pm SD & $(95 \%$ CI $)$ & Mean \pm SD & CI $(-95 \%)$ & \\
\hline age (years) & $11.10 \pm 2.84$ & $10.49-11.72$ & $10.70 \pm 3.13$ & $9.92-11.47$ & 0.389 \\
\hline body mass (kg) & $59.01 \pm 21.04$ & $54.47-63.55$ & $56.89 \pm 20.08$ & $52.00-61.9$ & 0.706 \\
\hline height $(\mathrm{cm})$ & $150.79 \pm 16.69$ & 147.19-154.39 & $149.31 \pm 18.29$ & $144.85-153.77$ & 0.660 \\
\hline BMI & $24.97 \pm 4.12$ & $24.08-25.86$ & $24.53 \pm 3.57$ & 23.66-25.41 & 0.759 \\
\hline BMI centile & $95.18 \pm 3.24$ & $94.49-95.88$ & $95.23 \pm 3.43$ & $94.41-96.06$ & 0.812 \\
\hline $\begin{array}{l}\text { no. of girls at } \\
\text { visit } 1\end{array}$ & \multicolumn{2}{|c|}{46} & \multicolumn{2}{|c|}{38} & 0.827 \\
\hline $\begin{array}{l}\% \text { of girls at } \\
\text { visit } 1\end{array}$ & \multicolumn{2}{|c|}{$54.12 \%$} & \multicolumn{2}{|c|}{$56.72 \%$} & \\
\hline
\end{tabular}

$p<0.05$ Mann-Whitney U test analysis. 


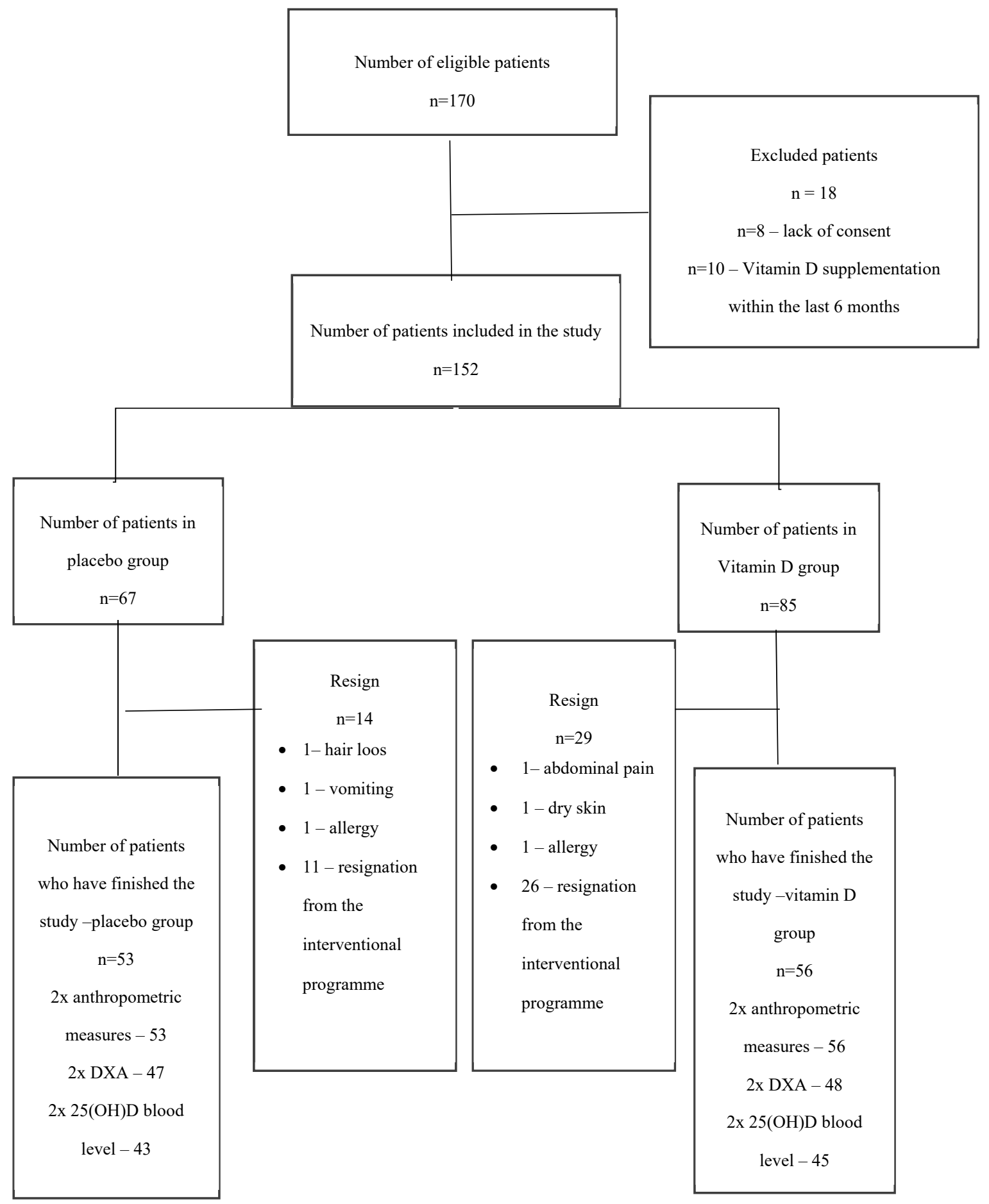

Figure 2. Patient flowchart in the study

There were no statistically significant differences between the vitamin $\mathrm{D}$ and placebo groups at the start of the study.

The differences between the groups in terms of main endpoints were subsequently assessed.

The results of basic anthropometric and 25(OH)D concentration tests are shown in Table 2. 
Table 2. Results of basic anthropometric and 25(OH)D concentration tests in studied groups.

\begin{tabular}{|c|c|c|c|c|c|c|c|}
\hline \multirow{2}{*}{ Variable } & \multicolumn{3}{|c|}{ vitamin D } & \multicolumn{3}{|c|}{ placebo } & \multirow[b]{2}{*}{$p$} \\
\hline & No & Mean \pm SD & $95 \%$ CI & No & Mean \pm & $95 \%$ CI & \\
\hline BMI visit 1 & 85 & $24.97 \pm 4.12$ & $24.08-25.86$ & 67 & $24.53 \pm 3.58$ & $23.66-25.41$ & 0.759 \\
\hline$\Delta \mathrm{BMI}$ visit $4-1$ & 56 & $-0.46 \pm 1.80$ & $-0.94-0.03$ & 53 & $0.11 \pm 1.84$ & $-0.40-0.61$ & 0.203 \\
\hline BMI centile 1 visit & 85 & $95.18 \pm 3.22$ & $94.49-95.88$ & 67 & $95.23 \pm 3.39$ & $94.41-96.06$ & 0.812 \\
\hline BMI centile 4 visit & 56 & $90.91 \pm 9.40$ & 88.39-93.43 & 53 & $92.64 \pm 7.53$ & $90.56-94.71$ & 0.303 \\
\hline $25(\mathrm{OH}) \mathrm{D}$ level visit 1 & 85 & $19.35 \pm 5.46$ & $18.16-20.55$ & 66 & $19.79 \pm 5.15$ & $18.52-21.06$ & $0.622 *$ \\
\hline $25(\mathrm{OH}) \mathrm{D}$ level visit 4 & 45 & $24.99 \pm 5.54$ & $23.33-26.66$ & 43 & $18.3 \pm 6.70$ & $16.25-20.37$ & $0.000 *$ \\
\hline$\Delta 25(\mathrm{OH})$ level visit $4-1$ & 45 & $6.06 \pm 5.80$ & $4.32-7.81$ & 43 & $-2.40 \pm 5.97$ & $-4.24--0.57$ & 0.000 * \\
\hline
\end{tabular}

$p<0.05$ Mann-Whitney $\mathrm{U}$ test, ${ }^{*} \mathrm{t}$-student test for independent samples.

The results of bioelectric impedance measurements are shown in Table 3.

Table 3. Results of bioelectric impedance measurements in studied groups.

\begin{tabular}{|c|c|c|c|c|c|c|c|}
\hline \multirow{2}{*}{ Variable } & \multicolumn{3}{|c|}{ vitamin $\mathrm{D}$} & \multicolumn{3}{|c|}{ placebo } & \multirow[b]{2}{*}{$p$} \\
\hline & No & Mean & CI (-95\%) & No & Mean & CI $(-95 \%)$ & \\
\hline BI_FM (kg) visit 1 & 82 & $18.32 \pm 8.01$ & 16.56-20.08 & 64 & $17.80 \pm 7.30$ & $15.97-19.62$ & 0.820 \\
\hline$\Delta$ BI_FM (kg) visit 4-1 & 54 & $-0.11 \pm 4.09$ & $-1.23-1.00$ & 51 & $0.01 \pm 4.01$ & $-1.11-1.14$ & 0.890 \\
\hline BI_FM (\%) visit 1 & 54 & $31.15 \pm 4.90$ & $29.81-32.48$ & 51 & $31.23 \pm 5.91$ & $29.57-32.89$ & 0.741 \\
\hline BI_FM (\%) visit 4 & 54 & $29.57 \pm 6.03$ & $27.92-31.21$ & 51 & $29.39 \pm 6.95$ & $27.44-31.35$ & $0.889^{*}$ \\
\hline BI_MM (kg) visit 1 & 82 & $38.46 \pm 14.00$ & $35.39-41.54$ & 64 & $37.10 \pm 13.65$ & $33.69-40.51$ & 0.586 \\
\hline BI_MM (kg) visit 4 & 56 & $40.12 \pm 12.85$ & $36.68-43.56$ & 53 & $40.80 \pm 12.92$ & $37.24-44.36$ & 0.886 \\
\hline$\Delta$ BI_MM (kg) visit 4-1 & 55 & $2.45 \pm 2.57$ & $1.75-3.14$ & 51 & $3.33 \pm 2.75$ & $2.56-4.10$ & 0.091 * \\
\hline BI_MM (\%) visit 1 & 82 & $65.69 \pm 5.39$ & $64.50-66.87$ & 64 & $65.48 \pm 5.03$ & $64.22-66.73$ & 0.350 \\
\hline BI_MM (\%) visit 4 & 56 & $66.63 \pm 5.68$ & $65.11-68.16$ & 53 & $66.81 \pm 6.52$ & $65.01-68.61$ & 0.896 \\
\hline
\end{tabular}

$p<0.05$ Mann-Whitney U test, ${ }^{*}$ t-student test for independent samples. BI-bioimpedance, FM-fat mass, $\Delta-$ delta-difference, MM-muscle mass.

The results of the dual X-ray absorptiometry (DXA) measurements are presented in Table 4.

Table 4. Results of dual X-ray absorptiometry (DXA) measurements in studied groups.

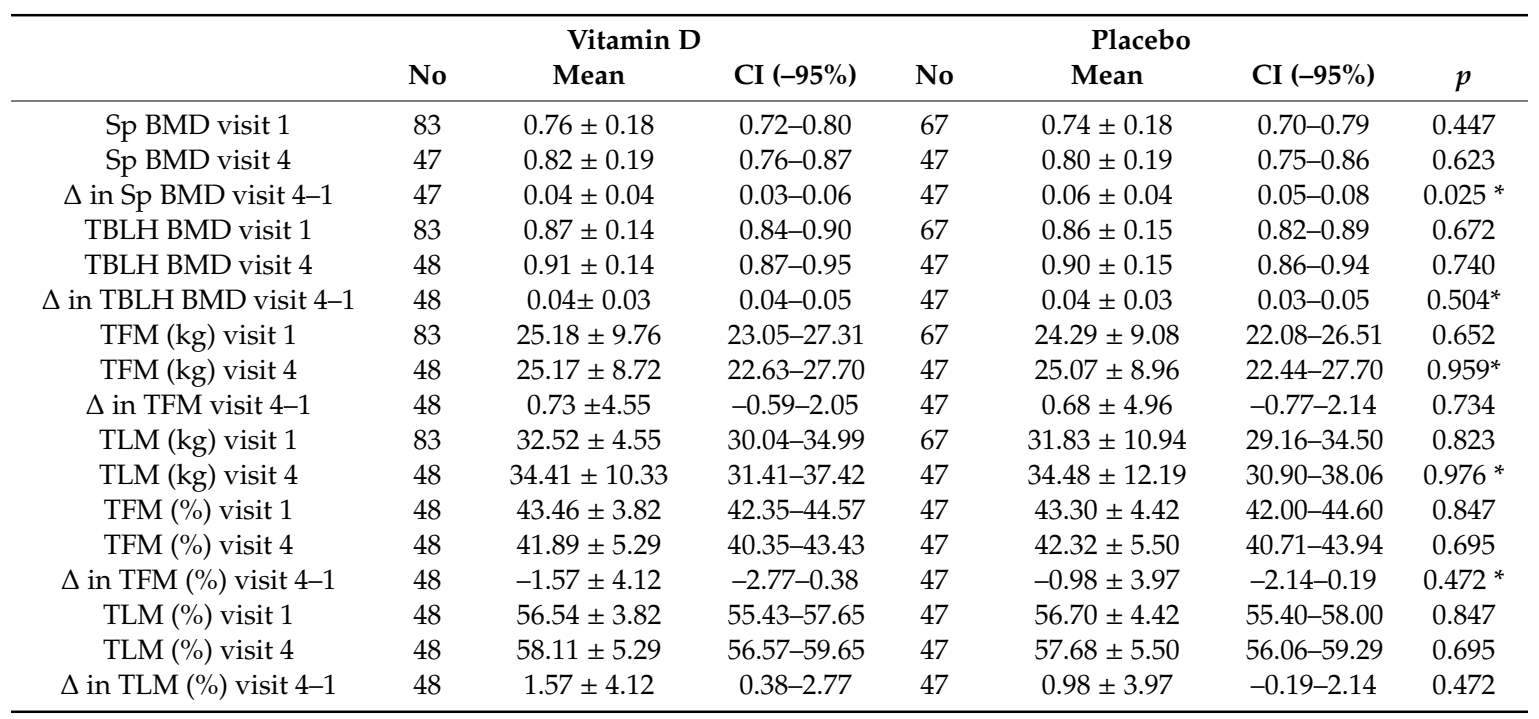

$p<0.05$ Mann-Whitney U test, ${ }^{*}$ t-student test for independent samples. Sp-spine, BMD—bone mineral density,

$\Delta$-delta-difference, TBLH—total body less head, TFM-total fat mass, TLM—total lean mass. 
Both groups had a reduction in BMI centiles. Although the reduction was greater in the vitamin D vs. placebo group $(-4.28 \pm 8.43$ vs. $-2.53 \pm 6.10)$ the difference was not statistically significant $(p=0.319)$. Similarly the reduction in fat mass-assessed both using bioimpedance and DEXa was achieved, yet the differences between the groups were not statistically significant, as shown in Tables 3 and 4 .

The analysis showed statistically significant differences between the groups only in $25(\mathrm{OH}) \mathrm{D} 3$ concentration in the measurements taken after the supplementation period (24.99 vs. $16.25 ; p=0.000)$ and in the difference between second and first measurement of vitamin D levels (6.06 vs. -4.24 ; $p=0.000$ ), and in the difference between second and first measurement of bone mineral density in the spine (Sp BMD) (0.04 vs. 0.06; $p<0.0256)$. The difference was higher in the placebo group.

There was no difference between the placebo group and the vitamin D group in BMI reduction, BMI centile, fat tissue in $\mathrm{kg}$ \% of fat tissue (assessed both by performing BIA and densitometry analysis).

Additionally, we have performed an analysis of correlations (Spearman rank correlation coefficient) between vitamin D levels at Visit 1 and 4 and changes of vitamin D level between the visits dependent on several anthropometric variables. Results are presented in Table 5.

Table 5. Correlation between vitamin D levels and anthropometric variables.

\begin{tabular}{|c|c|c|c|}
\hline & $25(\mathrm{OH})$ D Level Visit 1 & $25(\mathrm{OH})$ D Level Visit 4 & $\Delta 25(\mathrm{OH})$ Level Visit 4-1 \\
\hline BMI centile 1 visit & -0.088910 & -0.232998 & -0.066400 \\
\hline BMI centile 4 visit & -0.128452 & -0.297140 & -0.147392 \\
\hline$\Delta$ in BMI centiles visit $4-1$ & -0.059634 & -0.141315 & -0.138827 \\
\hline BI_FM (\%) visit 1 & -0.248164 & -0.238226 & -0.020100 \\
\hline BI_FM (\%) visit 4 & -0.213330 & -0.226632 & -0.019981 \\
\hline$\Delta$ BI_FM (\%) visit 4-1 & 0.073786 & -0.013645 & -0.058235 \\
\hline BI_MM (\%) visit 1 & 0.214256 & 0.202164 & -0.005444 \\
\hline BI_MM (\%) visit 4 & 0.204376 & 0.233062 & 0.045692 \\
\hline$\Delta$ BI_MM (\%) visit 4-1 & -0.077210 & 0.057706 & 0.107305 \\
\hline $25(\mathrm{OH}) \mathrm{D}$ level visit 1 & 1.000000 & 0.322476 & -0.426874 \\
\hline $25(\mathrm{OH}) \mathrm{D}$ level visit 4 & 0.322476 & 1.000000 & 0.692743 \\
\hline$\Delta 25(\mathrm{OH})$ level visit $4-1$ & -0.426874 & 0.692743 & 1.000000 \\
\hline TBLH BMD visit 1 & -0.357821 & -0.164349 & 0.102925 \\
\hline TBLH BMD visit 4 & -0.377036 & -0.222562 & 0.012532 \\
\hline$\Delta$ in TBLH BMD visit $4-1$ & 0.079692 & 0.007924 & -0.047583 \\
\hline TFM (\%) visit 1 & -0.177243 & -0.206046 & -0.111781 \\
\hline TFM (\%) visit 4 & -0.035164 & -0.122583 & -0.069020 \\
\hline$\Delta$ in TFM $(\%)$ visit $2-1$ & 0.174996 & -0.008749 & -0.047612 \\
\hline TLM (\%) visit 1 & 0.177243 & 0.206046 & 0.111781 \\
\hline TLM (\%) visit 4 & 0.035164 & 0.122583 & 0.069020 \\
\hline$\Delta$ in TLM $(\%)$ visit $4-1$ & -0.174996 & 0.008749 & 0.047612 \\
\hline
\end{tabular}

Spearman rank correlation coefficient; bolded when $p<0.05$, BI-bioimpedance, FM-fat mass, $\Delta$-delta-difference, MM—muscle mass, BMD—bone mineral density, TBLH—total body less head, TFM—total fat mass, TLM—total lean mass.

The results show that there were no important correlation between the initial BMI centile and vitamin $\mathrm{D}$ level at the first visit. Additionally the correlation did not show any significant influence of $\mathrm{BMI}$ changes on changes in vitamin $\mathrm{D}$ level after the supplementation period. There were significant negative correlations $(p<0.05)$ between fat mass \% and levels of vitamin $\mathrm{D}$ during both visits-which can confirm the relation between the fat mass and blood level of vitamin D. Yet this was a rather weak correlation (-0.25 to -0.21$)$. Further, it was not confirmed in DXA measurements.

\section{Discussion}

\subsection{Effect of Vitamin D Supplementation on Body Mass Reduction}

Presented study is the first randomized trial to assess potential effects of vitamin D supplementation in body mass reduction in overweight and obese children. Results of present study show that 
supplementation of vitamin D did not have a statistically significant, put potentially clinically important, influence on body mass (BMI, BMI centile) body composition or bone mineral density comparing to placebo groups during an organized obesity management program in children.

Biological role of vitamin D in etiopathogenesis of metabolic syndrome represents an interesting issue. Previous studies conducted among children revealed inverse relationship between blood concentration of vitamin D and waist circumference, systolic blood pressure, insulin resistance, fasting glucose, total cholesterol, triglycerides and LDL cholesterol, as well as positive association between the concentration of vitamin D and HDL cholesterol $[25,38,39]$. It seems that vitamin D can interfere with secretion of insulin both directly_binding to its receptors [VDR] on pancreatic $\beta$ cells, and indirectly by modulating concentration of calcium in extracellular space [40].

Importantly, a positive association between the concentration of vitamin $\mathrm{D}$ and sensitivity to insulin was observed in obese children, along with an inverse relationship between the level of this vitamin and concentration of glycated hemoglobin (HbA1c) [41]. Supplementation with vitamin D in obese adolescents resulted in decrease of insulin resistance, while levels of inflammatory markers [CRP, TNF- $\alpha$, IL-6] remained unchanged [42]. Till now, to the best of our knowledge, no studies were carried out in children or adolescents regarding the effects of vitamin D supplementation on body mass reduction during an organized lifestyle modification program. As we presented, adding a $1200 \mathrm{IU} /$ day dose of vitamin D did not lead to higher changes in BMI (BMI centile) or fat mass as well as fat free mass changes in children aged 6-14. It needs to be stated that the results presented show that although there was a reduction in BMI in vitamin D group compared to placebo group $(-0.46 \pm 1.80 \mathrm{vs}$. $0.11 \pm 1.84)$ and BMI centiles also showed higher reduction in children supplemented with vitamin $D$ $(-4.28 \pm 8.43$ vs. $-2.53 \pm 6.10)$ none of those results was statistically significant $(p=0.203$ and $p=0.319$ respectively). Similar results can be found in bioimpedance measurements, but not DXA assessment. Presented results would be presented as clinically valid. Although this 26-week long supplementation had an influence on blood concentration level of 25(OH) D in the active treatment group, only 6 out of all patients reached a level above $30 \mathrm{ng} / \mathrm{ml}$ in the final assessment ( 2 in the placebo group) 52 weeks after the start of the intervention. This shows that vitamin $\mathrm{D}$ can potentially have an impact on weight loss level but possibly due to resignation ratio or sample size we were not able to show that effect.

As previous studies in adolescents and adults showed, low ( 1000 IU/daily) or high doses (up to $300,000 \mathrm{IU} / \mathrm{month}$ ) of vitamin D supplementation have a very mixed results in influencing changes in fat mass, free fat mass or muscle mass [43-45]. Data regarding effect of vitamin D supplementation on body mass/body fat changes are limited to studies and meta-analyses/reviews regarding adults with wide range of interventions (medical weight loss, bariatric surgery, low-caloric diet) were used together with vitamin D supplementation. Additionally those studies were focused on finding the optimal dose of supplementation to reach the optimal (>30 ng/l) level of vitamin D [44] or assessing the association of vitamin level and body fat. Meta-analysis of studies in obese adults showed that although there was an impact of vitamin D supplementation on body fat, the results were not statistically significant [43]. This study also acknowledges that the impact of vitamin D supplementation on body fat reduction has a linear effect up to $2000 \mathrm{IU} / \mathrm{d}$, with no benefits in increasing the dose in adults. The only review regarding impact of vitamin D supplementation on bone mineral density was focused on general population-as no studies was directly focused on overweight/obese children. In addition, no sub-analysis was performed to show the effect depending on body mass. Winzenberg states that the impact of vitamin D supplementation can be higher in vitamin D deficient children, but the effect is small-in most studies standardized mean difference between groups was small $(<0,3)$ [45]. Yet all of these measures are only proxy measures to changes in body weight as a primary outcome of supplementation of vitamin D in obese children/adolescents. As for now, no studies have demonstrated effectiveness of such a strategy for supporting body fat reduction throughout a long-term interventional process. 


\subsection{Effect of Vitamin D Supplementation on Bone Mineral Density During Weight Loss}

Metabolic effects of obesity on growth and maturation of bones are still not fully understood. Moreover, the results of previous studies analyzing bone mass and density in obese individuals are highly inconclusive. While some authors claimed a decrease in bone mass relative to body weight [46], others did not document significant differences in bone mineral density [47] or showed an increase in body mass and bone size in obese children, adolescents and adults. Increased bone mass and density observed in obese individuals is postulated to be a response to greater mechanical load, direct influence of leptin or enhanced enzymatic activity of aromatase [48,49]. Nevertheless, obesity markedly increases the risk of bone fractures in children [50]. Vitamin D plays important biological role in the process of bone maturation and mineralization. Previous studies documented an inverse relationship between blood concentration of vitamin D and bone mineral density [51,52]. One meta-analysis revealed that supplementation of vitamin D can improve both bone mineral density and bone mass in individuals with low blood levels of this vitamin [45]. The effects of supplementation are particularly favorable in premenarcheal girls with normal body weight, in whom administration of vitamin D resulted in increases of both bone mass and fat-free mass [53]. An analysis of 58 morbidly obese teenagers showed that individuals with physiological blood concentration of PTH (parathyroid hormone) have normal bone mineral density, irrespectively of their vitamin D levels [54]. In contrast, a recently published study involving a small group of adolescents with obesity $(n=24)$ and normal body weight $(n=25)$ showed that obese people present with higher bone mineral density, irrespectively their blood concentration of vitamin D and despite lower level of physical activity than their normal-weight peers. Moreover, the differences in bone mineral density turned out to be independent from fat-free mass content. Furthermore, bone mineral density was associated with blood concentrations of leptin and insulin [55]. Our study shows clearly that we can observe an increase of bone mineral density both spinal and subtotal BMD with body mass reduction. Yet there is no impact of vitamin D supplementation on the level of bone density assessed using DXA. This shows that the body mass reduction itself impacts the bone mineralization the most.

Apart from many unquestioned favorable health effects of losing excessive weight, this process may also be associated with enhanced bone turnover and decrease in bone mineral density. In recently published systemic review, the decrease of bone mass was reported following calorie-restricting diet but not in exercise-induced weight-loss [56]. However, this evidence originates mostly from studies conducted among adults [57-59], and to the best of our knowledge, the issue in question was a subject of only one study of adolescents after bariatric surgeries [60]. The results from previous intervention studies suggest that a low-calorie albeit high-protein (ca. 30\%) diet, containing high amounts of dairy products, can prevent the loss of bone mass and a decrease in bone mineralization [61]. Yet supplementation with high doses of vitamin D can have a negative effect on bone mineralization in adults-as a recent study by Burt et al. showed [62].

Study limitations:

This study has some limitations that need to be taken into account when assessing the usefulness of the results:

- Children aged 6-14 years old were included in the study-this is not a homogenic group when it comes to maturation/puberty status-and this has an impact on both the ability to decrease body mass and bone turnover and mineralization;

- We were giving one dose of vitamin D (1200 IU) to all participants independent the body mass and age, which could have result in less effective increase of $25(\mathrm{OH}) \mathrm{D}$ level, which in turn could have impacted the changes in body mass or bone mineral density;

- 26 weeks may be too short to establish the effects of vitamin D supplementation on the rate of skeletal mineralization

- There was an almost 30\% drop-out, seen especially in the second part of the program-after finishing the active supplementation with vitamin D/placebo period. This was unlikely to be due to the treatment itself (as there were no important side effects registered). The level of lost to follow-up 
patients in the interventional program is similar to other such programs seen in Poland and other European countries $[63,64]$.

- Finally, the sample sizes were smaller than anticipated and there is a possibility that with the estimated reduction of $10 \%$ of BMI reduction the study sample is underestimated. It is possible that the study was underpowered to detect smaller changes in BMI/BMI centiles as well as other parameters.

\section{Conclusions}

Available data on the efficacy of vitamin supplementation during weight loss are inconclusive and mostly limited to adults. Our study shows that there is a limited or no effect of vitamin D supplementation on body weight reduction in children and adolescents with vitamin D insufficiency. Being aware and understanding the potential limitation of our study-wide age group, one dose of vitamin D, small sample of the study we believe that further research in this field is needed.

Author Contributions: M.B. participated in the study design and coordination of the study, performed the statistical data analysis, drafted the paper and revised and approved the manuscript; A.J., M.S.-F., P.M., and P.W. participated in the study design, patient recruitment, data collection, revised and approved the manuscript; P.S. participated in the study design and revised and approved the manuscript; A.S.-S. participated in the study design and coordination of the study, data analysis, drafted, revised and approved the manuscript. All authors have read and agreed to the published version of the manuscript.

Funding: The study was awarded a financial grant from a charitable foundation (Fundacja Nutricia) Grant no RG-1/2015. The Fundacja Nutricia did not take part in any element of study design or study realization such as the study design or; collection, management, analysis, and interpretation of data; writing of the report; and the decision to submit the report for publication.

Acknowledgments: All authors would like to sincerely thank all participant, parents and members of the "6-10-14 for Health" team for their input into the study. Authors would also like to thank University Clinical Centre administration for help in performing the study.

Conflicts of Interest: The authors declare no conflicts of interest.

\section{References}

1. Bentham, J.; Di Cesare, M.; Bilano, V.; Bixby, H.; Zhou, B.; Stevens, G.A.; Riley, L.M.; Taddei, C.; Hajifathalian, K.; Lu, Y.; et al. Worldwide trends in body-mass index, underweight, overweight, and obesity from 1975 to 2016: A pooled analysis of 2416 population-based measurement studies in 128.9 million children, adolescents, and adults. Lancet 2017, 390, 2627-2642.

2. Ng, M.; Fleming, T.; Robinson, M.; Thomson, B.; Graetz, N.; Margono, C.; Mullany, E.C.; Biryukov, S.; Abbafati, C.; Abera, S.F.; et al. Global, regional, and national prevalence of overweight and obesity in children and adults during 1980-2013: A systematic analysis for the Global Burden of Disease Study 2013. Lancet 2014, 384, 766-781. [CrossRef]

3. Bann, D.; Johnson, W.; Li, L.; Kuh, D.; Hardy, R. Socioeconomic inequalities in childhood and adolescent body-mass index, weight, and height from 1953 to 2015: An analysis of four longitudinal, observational, British birth cohort studies. Lancet Public Health 2018, 3, e194-e203. [CrossRef]

4. Kumar, S.; Kelly, A.S. Review of Childhood Obesity: From Epidemiology, Etiology, and Comorbidities to Clinical Assessment and Treatment. Mayo Clin. Proc. 2017, 92, 251-265. [CrossRef] [PubMed]

5. Kelly, A.S.; Barlow, S.E.; Rao, G.; Inge, T.H.; Hayman, L.L.; Steinberger, J.; Urbina, E.M.; Ewing, L.J.; Daniels, S.R. Severe obesity in children and adolescents: Identification, associated health risks, and treatment approaches: A scientific statement from the American Heart Association. Circulation 2013, 128, 1689-1712. [CrossRef] [PubMed]

6. Kinlen, D.; Cody, D.; O'Shea, D. Complications of obesity. QJM An Int. J. Med. 2018, 111, 437-443. [CrossRef]

7. Di Angelantonio, E.; Bhupathiraju, S.; Wormser, D.; Gao, P.; Kaptoge, S.; Berrington de Gonzalez, A.; Cairns, B.; Huxley, R.; Jackson, C.; et al.; Global BMI Mortality Collaboration Body-mass index and all-cause mortality: Individual-participant-data meta-analysis of 239 prospective studies in four continents. Lancet 2016, 388, 776-786. [CrossRef] 
8. Brown, T.; Moore, T.H.; Hooper, L.; Gao, Y.; Zayegh, A.; Ijaz, S.; Elwenspoek, M.; Foxen, S.C.; Magee, L.; O'Malley, C.; et al. Interventions for preventing obesity in children. Cochrane Database Syst. Rev. 2019, 2019. [CrossRef]

9. Nemet, D.; Levi, L.; Pantanowitz, M.; Eliakim, A. A combined nutritional-behavioral-physical activity intervention for the treatment of childhood obesity-A 7-year summary. J. Pediatr. Endocrinol. Metab. 2014, 27, 445-451. [CrossRef]

10. Oude Luttikhuis, H.; Baur, L.; Jansen, H.; Shrewsbury, V.A.; O’Malley, C.; Stolk, R.P.; Summerbell, C.D. Interventions for treating obesity in children. Cochrane Database Syst. Rev. 2019, 3, CD001872. [CrossRef]

11. Masquio, D.C.L.; De Piano, A.; Campos, R.M.S.; Sanches, P.L.; Carnier, J.; Corgosinho, F.C.; Netto, B.D.M.; Carvalho-Ferreira, J.P.; Oyama, L.M.; Nascimento, C.M.O.; et al. The role of multicomponent therapy in the metabolic syndrome, inflammation and cardiovascular risk in obese adolescents. Br. J. Nutr. 2015, 113, 1920-1930. [CrossRef] [PubMed]

12. Ferreira, Y.A.M.; Kravchychyn, A.C.P.; Vicente, S.d.C.F.; Campos, R.M.d.S.; Tock, L.; Oyama, L.M.; Boldarine, V.T.; Masquio, D.C.L.; Thivel, D.; Shivappa, N.; et al. An interdisciplinary weight loss program improves body composition and metabolic profile in adolescents with obesity: Associations with the dietary inflammatory index. Front. Nutr. 2019, 6, 77. [CrossRef] [PubMed]

13. Reinehr, T. Calculating cardiac risk in obese adolescents before and after onset of lifestyle intervention. Expert Rev. Cardiovasc. Ther. 2013, 11, 297-306. [CrossRef] [PubMed]

14. Masquio, D.C.L.; De Piano, A.; Sanches, P.L.; Corgosinho, F.C.; Campos, R.M.S.; Carnier, J.; Da Silva, P.L.; Caranti, D.A.; Tock, L.; Oyama, L.M.; et al. The effect of weight loss magnitude on pro-/anti-inflammatory adipokines and carotid intima-media thickness in obese adolescents engaged in interdisciplinary weight loss therapy. Clin. Endocrinol. 2013, 79, 55-64. [CrossRef]

15. Cuda, S.E.; Censani, M. Pediatric Obesity Algorithm: A Practical Approach to Obesity Diagnosis and Management. Front. Pediatr. 2019, 6, 431. [CrossRef]

16. Boland, C.L.; Harris, J.B.; Harris, K.B. Pharmacological Management of Obesity in Pediatric Patients. Ann. Pharmacother. 2015, 49, 220-232. [CrossRef]

17. Domecq, J.P.; Prutsky, G.; Leppin, A.; Sonbol, M.B.; Altayar, O.; Undavalli, C.; Wang, Z.; Elraiyah, T.; Brito, J.P.; Mauck, K.F.; et al. Drugs commonly associated with weight change: A systematic review and meta-analysis. J. Clin. Endocrinol. Metab. 2015, 100, 363-370. [CrossRef]

18. Pooyandjoo, M.; Nouhi, M.; Shab-Bidar, S.; Djafarian, K.; Olyaeemanesh, A. The effect of (L-)carnitine on weight loss in adults: A systematic review and meta-analysis of randomized controlled trials. Obes. Rev. 2016, 17, 970-976. [CrossRef]

19. Huang, J.; Wang, Y.; Xie, Z.; Zhou, Y.; Zhang, Y.; Wan, X. The anti-obesity effects of green tea in human intervention and basic molecular studies. Eur. J. Clin. Nutr. 2014, 68, 1075-1087. [CrossRef]

20. Kim, S.Y.; Oh, M.R.; Kim, M.G.; Chae, H.J.; Chae, S.W. Anti-obesity effects of Yerba Mate (Ilex Paraguariensis): A randomized, double-blind, placebo-controlled clinical trial. BMC Complement. Altern. Med. 2015, 15, 338. [CrossRef]

21. Zalewski, B.M.; Szajewska, H. No Effect of Glucomannan on Body Weight Reduction in Children and Adolescents with Overweight and Obesity: A Randomized Controlled Trial. J. Pediatr. 2019, 211, 85-91. [CrossRef] [PubMed]

22. De Luis, D.; Domingo, J.C.; Izaola, O.; Casanueva, F.F.; Bellido, D.; Sajoux, I. Effect of DHA supplementation in a very low-calorie ketogenic diet in the treatment of obesity: A randomized clinical trial. Endocrine 2016, 54, 111-122. [CrossRef] [PubMed]

23. Lerchbaum, E.; Trummer, C.; Theiler-Schwetz, V.; Kollmann, M.; Wölfler, M.; Pilz, S.; Obermayer-Pietsch, B. Effects of vitamin D supplementation on body composition and metabolic risk factors in men: A randomized controlled trial. Nutrients 2019, 11, 1894. [CrossRef] [PubMed]

24. Al-Daghri, N.M.; Amer, O.E.; Khattak, M.N.K.; Sabico, S.; Ghouse Ahmed Ansari, M.; Al-Saleh, Y.; Aljohani, N.; Alfawaz, H.; Alokail, M.S. Effects of different vitamin D supplementation strategies in reversing metabolic syndrome and its component risk factors in adolescents. J. Steroid Biochem. Mol. Biol. 2019, 191, 105378. [CrossRef] [PubMed]

25. Aypak, C.; Türedi, Ö.; Yüce, A. The association of vitamin D status with cardiometabolic risk factors, obesity and puberty in children. Eur. J. Pediatr. 2014, 173, 367-373. [CrossRef] 
26. Lee, D.Y.; Kwon, A.R.; Ahn, J.M.; Kim, Y.J.; Chae, H.W.; Kim, D.H.; Kim, H.-S. Relationship between serum 25-hydroxyvitamin D concentration and risks of metabolic syndrome in children and adolescents from Korean National Health and Nutrition Examination survey 2008-2010. Ann. Pediatr. Endocrinol. Metab. 2015, 20, 46. [CrossRef]

27. Voortman, T.; van den Hooven, E.H.; Heijboer, A.C.; Hofman, A.; Jaddoe, V.W.; Franco, O.H. Vitamin D Deficiency in School-Age Children Is Associated with Sociodemographic and Lifestyle Factors. J. Nutr. 2015, 145, 791-798. [CrossRef]

28. Kamycheva, E.; Joakimsen, R.M.; Jorde, R. Intakes of Calcium and Vitamin D Predict Body Mass Index in the Population of Northern Norway. J. Nutr. 2003, 133, 102-106. [CrossRef]

29. Pourshahidi, L.K. Vitamin D and obesity: Current perspectives and future directions. In Proceedings of the Nutrition Society; Cambridge University Press: Cambridge, UK, 2015; Volume 74, pp. 115-124.

30. Engberg, E.; Figueiredo, R.A.O.; Rounge, T.B.; Weiderpass, E.; Viljakainen, H. Heavy screen users are the heaviest among 10,000 children. Sci. Rep. 2019, 9, 11158. [CrossRef]

31. Pacifico, L.; Anania, C.; Osborn, J.F.; Ferraro, F.; Bonci, E.; Olivero, E.; Chiesa, C. Low 25(OH)D3 levels are associated with total adiposity, metabolic syndrome, and hypertension in Caucasian children and adolescents. Eur. J. Endocrinol. 2011, 165, 603-611. [CrossRef]

32. Rosenstreich, S.J.; Rich, C.; Volwiler, W. Deposition in and release of vitamin D3 from body fat: Evidence for a storage site in the rat. J. Clin. Invest. 1971, 50, 679-687. [CrossRef] [PubMed]

33. Fu, J.; Han, L.; Zhao, Y.; Li, G.; Zhu, Y.; Li, Y.; Li, M.; Gao, S.; Willi, S.M. Vitamin D levels are associated with metabolic syndrome in adolescents and young adults: The BCAMS study. Clin. Nutr. 2019, 38, 2161-2167. [CrossRef] [PubMed]

34. Denova-Gutiérrez, E.; Muñoz-Aguirre, P.; López, D.; Flores, M.; Medeiros, M.; Tamborrel, N.; Clark, P. Low serum vitamin D concentrations are associated with insulin resistance in Mexican children and adolescents. Nutrients 2019, 11, 2109. [CrossRef] [PubMed]

35. Mitri, J.; Nelson, J.; Ruthazer, R.; Garganta, C.; Nathan, D.M.; Hu, F.B.; Dawson-Hughes, B.; Pittas, A.G. Plasma 25-hydroxyvitamin D and risk of metabolic syndrome: An ancillary analysis in the Diabetes Prevention Program. Eur. J. Clin. Nutr. 2014, 68, 376-383. [CrossRef]

36. Szlagatys-Sidorkiewicz, A.; Brzeziński, M.; Jankowska, A.; Metelska, P.; Słomińska-Fraczek, M.; Socha, P. Long-term effects of vitamin D supplementation in vitamin D deficient obese children participating in an integrated weight-loss programme (a double-blind placebo-controlled study)—Rationale for the study design. BMC Pediatr. 2017, 17, 97. [CrossRef]

37. Kułaga, Z.; Litwin, M.; Tkaczyk, M.; Palczewska, I.; Zajączkowska, M.; Zwolińska, D.; Krynicki, T.; Wasilewska, A.; Moczulska, A.; Morawiec-Knysak, A.; et al. Polish 2010 growth references for school-aged children and adolescents. Eur. J. Pediatr. 2011, 170, 599-609. [CrossRef]

38. Reyman, M.; Verrijn Stuart, A.A.; Van Summeren, M.; Rakhshandehroo, M.; Nuboer, R.; De Boer, F.K.; Van Den Ham, H.J.; Kalkhoven, E.; Prakken, B.; Schipper, H.S. Vitamin D deficiency in childhood obesity is associated with high levels of circulating inflammatory mediators, and low insulin sensitivity. Int. J. Obes. 2014, 38, 46-52. [CrossRef]

39. Ganji, V.; Zhang, X.; Shaikh, N.; Tangpricha, V. Serum 25-hydroxyvitamin D concentrations are associated with prevalence of metabolic syndrome and various cardiometabolic risk factors in US children and adolescents based on assay-adjusted serum 25-hydroxyvitamin D data from NHANES 2001-2006. Am. J. Clin. Nutr. 2011, 94, 225-233. [CrossRef]

40. Song, Y.; Wang, L.; Pittas, A.G.; Del Gobbo, L.C.; Zhang, C.; Manson, J.E.; Hu, F.B. Blood 25-Hydroxy Vitamin D Levels and Incident Type 2 Diabetes. Diabetes Care 2013, 36, 1422-1428. [CrossRef]

41. Alemzadeh, R.; Kichler, J.; Babar, G.; Calhoun, M. Hypovitaminosis D in obese children and adolescents: Relationship with adiposity, insulin sensitivity, ethnicity, and season. Metabolism 2008, 57, 183-191. [CrossRef]

42. Belenchia, A.M.; Tosh, A.K.; Hillman, L.S.; Peterson, C.A. Correcting vitamin D insufficiency improves insulin sensitivity in obese adolescents: A randomized controlled trial. Am. J. Clin. Nutr. 2013, 97, 774-781. [CrossRef] [PubMed]

43. Golzarand, M.; Hollis, B.W.; Mirmiran, P.; Wagner, C.L.; Shab-Bidar, S. Vitamin D supplementation and body fat mass: A systematic review and meta-analysis. Eur. J. Clin. Nutr. 2018, 72, 1345-1357. [CrossRef]

44. Bassatne, A.; Chakhtoura, M.; Saad, R.; Fuleihan, G.E.H. Vitamin D supplementation in obesity and during weight loss: A review of randomized controlled trials. Metabolism 2019, 92, 193-205. [CrossRef] [PubMed] 
45. Winzenberg, T.; Powell, S.; Shaw, K.A.; Jones, G. Effects of vitamin D supplementation on bone density in healthy children: Systematic review and meta-analysis. BMJ 2011, 342, 267. [CrossRef] [PubMed]

46. Goulding, A.; Taylor, R.W.; Jones, I.E.; McAuley, K.A.; Manning, P.J.; Williams, S.M. Overweight and obese children have low bone mass and area for their weight. Int. J. Obes. 2000, 24, 627-632. [CrossRef] [PubMed]

47. El Hage, R.; El Hage, Z.; Jacob, C.; Moussa, E.; Theunynck, D.; Baddoura, R. Bone Mineral Content and Density in Overweight and Control Adolescent Boys. J. Clin. Densitom. 2011, 14, 122-128. [CrossRef]

48. McVey, M.K.; Geraghty, A.A.; O’Brien, E.C.; McKenna, M.J.; Kilbane, M.T.; Crowley, R.K.; Twomey, P.J.; McAuliffe, F.M. The impact of diet, body composition, and physical activity on child bone mineral density at five years of age-Findings from the ROLO Kids Study. Eur. J. Pediatr. 2020, 179, 121-131. [CrossRef]

49. Rønne, M.S.; Heidemann, M.; Lylloff, L.; Schou, A.J.; Tarp, J.; Laursen, J.O.; Jørgensen, N.R.; Husby, S.; Wedderkopp, N.; Mølgaard, C. Bone Mass Development in Childhood and Its Association with Physical Activity and Vitamin D Levels. The CHAMPS-Study DK. Calcif. Tissue Int. 2019, 104, 1-13. [CrossRef]

50. Kessler, J.; Koebnick, C.; Smith, N.; Adams, A. Childhood obesity is associated with increased risk of most lower extremity fractures pediatrics. Clin. Orthop. Relat. Res. 2013, 471, 1199-1207. [CrossRef]

51. Cashman, K.D.; Hill, T.R.; Cotter, A.A.; Boreham, C.A.; Dubitzky, W.; Murray, L.; Strain, J.J.; Flynn, A.; Robson, P.J.; Wallace, J.M.; et al. Low vitamin D status adversely affects bone health parameters in adolescents 1-3. Am. J. Clin. Nutr. 2008, 87, 1039-1044. [CrossRef]

52. Pekkinen, M.; Viljakainen, H.; Saarnio, E.; Lamberg-Allardt, C.; Mäkitie, O. Vitamin D is a major determinant of bone mineral density at school age. PLoS ONE 2012, 7, e40090. [CrossRef] [PubMed]

53. Fuleihan, G.E.H.; Nabulsi, M.; Tamim, H.; Maalouf, J.; Salamoun, M.; Khalife, H.; Choucair, M.; Arabi, A.; Vieth, R. Effect of vitamin D replacement on musculoskeletal parameters in school children: A randomized controlled trial. J. Clin. Endocrinol. Metab. 2006, 91, 405-412. [CrossRef] [PubMed]

54. Lenders, C.M.; Feldman, H.A.; Von Scheven, E.; Merewood, A.; Sweeney, C.; Wilson, D.M.; Lee, P.D.K.; Abrams, S.H.; Gitelman, S.E.; Wertz, M.S.; et al. Relation of body fat indexes to vitamin D status and deficiency among obese adolescents. Am. J. Clin. Nutr. 2009, 90, 459-467. [PubMed]

55. Maggio, A.B.R.; Belli, D.C.; Puigdefabregas, J.W.B.; Rizzoli, R.; Farpour-Lambert, N.J.; Beghetti, M.; McLin, V.A. High bone density in adolescents with obesity is related to fat mass and serum leptin concentrations. J. Pediatr. Gastroenterol. Nutr. 2014, 58, 723-728. [PubMed]

56. Soltani, S.; Hunter, G.R.; Kazemi, A.; Shab-Bidar, S. The effects of weight loss approaches on bone mineral density in adults: A systematic review and meta-analysis of randomized controlled trials. Osteoporos. Int. 2016, 27, 2655-2671. [CrossRef]

57. Rector, R.S.; Loethen, J.; Ruebel, M.; Thomas, T.R.; Hinton, P.S. Serum markers of bone turnover are increased by modest weight loss with or without weight-bearing exercise in overweight premenopausal women. Appl. Physiol. Nutr. Metab. 2009, 34, 933-941. [CrossRef]

58. Lindeman, K.G.; Greenblatt, L.B.; Rourke, C.; Bouxsein, M.L.; Finkelstein, J.S.; Yu, E.W. Longitudinal 5-year evaluation of bone density and microarchitecture after Roux-en-Y gastric bypass surgery. J. Clin. Endocrinol. Metab. 2018, 103, 4104-4112. [CrossRef]

59. Elaine, W.Y.; Bouxsein, M.L.; Putman, M.S.; Monis, E.L.; Roy, A.E.; Pratt, J.S.A.; Butsch, W.S.; Finkelstein, J.S. Two-year changes in bone density after Roux-en-Y gastric bypass surgery. J. Clin. Endocrinol. Metab. 2015, 100, 1452-1459.

60. Kaulfers, A.M.D.; Bean, J.A.; Inge, T.H.; Dolan, L.M.; Kalkwarf, H.J. Bone loss in adolescents after bariatric surgery. Pediatrics 2011, 127, e956-e961. [CrossRef]

61. Labouesse, M.A.; Gertz, E.R.; Piccolo, B.D.; Souza, E.C.; Schuster, G.U.; Witbracht, M.G.; Woodhouse, L.R.; Adams, S.H.; Keim, N.L.; Van Loan, M.D. Associations among endocrine, inflammatory, and bone markers, body composition and weight loss induced bone loss. Bone 2014, 64, 138-146. [CrossRef]

62. Burt, L.A.; Billington, E.O.; Rose, M.S.; Raymond, D.A.; Hanley, D.A.; Boyd, S.K. Effect of high-dose vitamin D supplementation on volumetric bone density and bone strength: A randomized clinical trial. JAMA J. Am. Med. Assoc. 2019, 322, 736-745. [CrossRef] [PubMed] 
63. Inelmen, E.M.; Toffanello, E.D.; Enzi, G.; Gasparini, G.; Miotto, F.; Sergi, G.; Busetto, L. Predictors of drop-out in overweight and obese outpatients. Int. J. Obes. 2005, 29, 122-128. [CrossRef] [PubMed]

64. Ortner Hadžiabdić, M.; Mucalo, I.; Hrabač, P.; Matić, T.; Rahelić, D.; Božikov, V. Factors predictive of drop-out and weight loss success in weight management of obese patients. J. Hum. Nutr. Diet. 2015, 28, 24-32. [CrossRef] [PubMed]

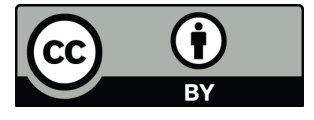

(C) 2020 by the authors. Licensee MDPI, Basel, Switzerland. This article is an open access article distributed under the terms and conditions of the Creative Commons Attribution (CC BY) license (http://creativecommons.org/licenses/by/4.0/). 